Editorial

\title{
Increased atrial myocardium vulnerability and sudden death in the wolff-parkinson-white syndrome
}

Volume 6 Issue I - 2016

\section{Editorial}

Historically, atrial fibrillation (AF) has passed from being the most frequent, older, and forgotten arrhythmia last century, to become the more investigated arrhythmia in this new millennium. Atrial premature contractions (APC) occurring in a critical timing during the relative atrial refractory period, in the presence of a nonhomogeneous dispersion of refractoriness and conduction, can trigger atrial responses that determine atrial vulnerability and susceptibility to develop AF. ${ }^{1-5}$ These atrial responses to clinical spontaneous APC can be reproduced in the electrophysiological laboratory. Indeed, the recording of abnormally prolonged and fractionated atrial electrograms by the technique of atrial endocardial mapping during sinus rhythm, as well as, the induction of electrophysiological responses by programmed atrial stimulation with single extra stimulus have shed very interesting data for a better comprehension of the atrial myocardial substrate in the genesis of $\mathrm{AF}^{6-13}$

Patients with the Wolff-Parkinson-White (WPW) syndrome are known to have an increased susceptibility to develop AF in the course of their lives. It has been shown a clear association between increased atrial vulnerability and the presence of a Kent accessory pathway (AP). Since the initial publication of the WPW syndrome, the investigators recognized the existence of an association between this entity and AF. ${ }^{1}$ Episodes of AF have been documented in one third of the patients with WPW syndrome. ${ }^{2}$ The AF in patients with this syndrome is associated with faster rates of the reciprocal tachycardia, with shorter effective refractory periods of the accessory pathway, slower intra-atrial conduction times, structural heart disease and advancing age. ${ }^{2-4}$ Patients with manifest pre-excitation that have spontaneous episodes of AF present a greater incidence of induction of AF by programmed atrial stimulation.

Not only the atrial vulnerability, but also the AP plays an important role in the development of AF. ${ }^{14}$ Therefore, it is very important to determine the influence of the AP and the presence of increased atrial vulnerability and the predisposition to develop AF. There are certain electrophysiological responses that can be induced by programmed atrial stimulation during the electrophysiological study which can be utilized as indicators of increased atrial muscle vulnerability. The programmed atrial stimulation is performed using a programmable electric stimulator with rectangular current pulses of $2 \mathrm{~ms}$ duration at twice the diastolic threshold. Programmed single premature atrial stimuli can be delivered after a train of eight atrial paced beats at two different cycle length from the high right atrium. The coupling interval between S1 and S2 is decreased in $10 \mathrm{~ms}$ steps until S2 is no longer captured, that is the atrial refractory period. Reaching the relative atrial refractoriness at a critical coupling timing, atrial responses are elicited in patients with increased atrial vulnerability and predisposition to develop AF.

Induction of AF can be achieved by incremental atrial rapid pacing and by programmed atrial stimulation with single extra stimulus.

\section{Osmar Antonio Centurión}

Department of Health Sciences?s Investigation, Sanatorio Metropolitano, Fernando de la Mora, Paraguay

Correspondence: Osmar Antonio Centurión, Professor of Medicine, Asuncion National University, Department of Health Sciences Investigation, Sanatorio Metropolitano, Teniente Ettiene $215 \mathrm{c} /$ Ruta Mariscal Estigarribia, Fernando de la Mora, Paraguay, Email osmarcenturion@hotmail.com

Received: June 07, 2016 | Published: June 28, 2016

With this latter approach certain electrophysiological parameters of increased atrial vulnerability can be induced, namely, repetitive atrial firing (RAF), fragmented atrial activity (FAA), and inter-atrial conduction delay (IACD). ${ }^{15-22}$ These electrophysiological responses in the site of stimulation reproduce in the laboratory the response of the atrial myocardium to clinical spontaneous APC that the patients may have in their daily routine. The APC can induce an important delay in conduction of the impulses and non homogeneous dispersion of atrial refractory periods developing an episode of sustained $\mathrm{AF}^{20}$ It is conceivable that these electrophysiological responses are the abnormal manifestation of cellular electrophysiology because they are found in pathologic tissue. Repetitive atrial firing is defined as the occurrence of two or more successive atrial complexes with a return cycle of $<250 \mathrm{~ms}$, and a subsequent cycle length of $<300 \mathrm{~ms} .{ }^{10}$ The interval between the longest and shortest coupling interval that elicited RAF is often referred as the zone. Hence, the longest and shortest coupling interval eliciting RAF are considered the outer and inner limits of the zone of induction of RAF. Fragmented atrial activity elicited by atrial extra stimulus is defined as the occurrence of disorganized atrial activity $\geq 150 \%$ of the duration of the local atrial electrogram of the basic beat recorded in the right atrium. ${ }^{21}$ The duration of the atrial activity in FAA is measured as the time interval comprised between the stimulus artifact and the end of the local electrogram in the high right atrium of the basic stimulus (A1) and the early single extra stimulus (A2). The inter-atrial conduction time is measured from the stimulus artifact to the atrial electrogram at the distal coronary sinus level. The inter-atrial conduction delay is defined as an increase in the 
$\mathrm{S}_{2}$ through $\mathrm{A}_{2}$ interval of the extra stimulus $20 \mathrm{~ms}$ compared with the $\mathrm{S}_{1}$ through $\mathrm{A}_{1}$ of the basic drive. These electrophysiological parameters can be considered as a clinical index in the AF prediction. ${ }^{23-26}$ The slowing of intra-atrial conduction is considered to be one of the most important requirements for the initiation of reentry and, thus, for AF to develop. ${ }^{26}$ These electrophysiological parameters have been evaluated in an individual manner and in heterogeneous groups of patients with multiple types of arrhythmias.

There is an important electrophysiological evidence of an underlying atrial disease in patients with the WPW syndrome. Abnormally prolonged and fractionated atrial endocardial electro grams are observed with a significantly higher incidence in WPW patients with documented episodes of AF. In addition, the electrophysiological findings of altered atrial refractoriness, increased induction of RAF and FAA, and wider zones of induction, as well as, an increased inter-atrial conduction delay suggest an intrinsic increased atrial vulnerability as the mechanism of PAF in certain patients with the WPW syndrome.

Dreifus et al. ${ }^{27}$ demonstrated a diffuse atrial destruction and a marked increased in connective tissue in the sinus node and the atria of WPW patients that had AF before the episode of sudden death. ${ }^{27}$ Wyndham et al. ${ }^{28}$ demonstrated that the shortening of the atrial cycle length is related to the atrial vulnerability. ${ }^{28}$ Rinne et al. ${ }^{29}$ observed that patients with WPW syndrome and AF had a higher incidence of atrial vulnerability than those WPW patients without $\mathrm{AF}^{29}$ Sung et al., ${ }^{30}$ demonstrated that the development of AF in the WPW syndrome may be related to the presence of atrial vulnerability. ${ }^{30}$ During AF in a WPW patient, the increasing rate of atrial depolarization in the presence of an AP with fast conduction capacity, the ventricles are exposed to very fast rates that can easily degenerate into ventricular tachycardia or fibrillation. That is, the electrophysiological phenomenon of conversion of an orthodromic tachycardia to $\mathrm{AF}$ identifies a group of patients that are at high risk of developing sudden death in the WPW syndrome. Similarly, those patients that have an increased atrial vulnerability and a predisposition to develop AF in the presence of a fast conducting AP can develop high ventricular rates that generates in a fatal episode of ventricular fibrillation and sudden death.

\section{Acknowledgments}

None.

\section{Conflicts of interest}

None.

\section{Funding}

None.

\section{References}

1. Wolff L, Parkinson J, White PD. Bundle branch block with short PR interval in healthy young people prone to paroxysmal tachycardia. $\mathrm{Am}$ Heart J. 1930;5(6):685-704

2. Wellens HJJ, Durrer D. Wolff-Parkinson-White syndrome and atrial fibrillation: Relation between refractory period of the accessory pathway and ventricular rate during atrial fibrillation. Am J Cardiol. 1974;34(7):777-782.

3. Chen PS, Pressley JC, Tang AS, et al. New observation on atrial fibrillation in patients with the Wolff-Parkinson-White syndrome. $J$ Am Coll Cardiol. 1992;19(5):974-981
4. Fujimura O, Klein JG, Yee R, et al. Mode of onset of atrial fibrillation in the Wolff-Parkinson-White syndrome: How important is the accessory pathway? J Am Coll Cardiol. 1990;15(5):1052-1056.

5. Luck JC, Engel TR. Dispersion of atrial refractoriness in patients with sinus node dysfunction. Circulation. 1979;60(4):404-412.

6. Centurión OA, Fukatani M, Konoe A, et al. Different distribution of abnormal endocardial atrial electrograms within the right atrium in patients with sick sinus syndrome. Br Heart J. 1992; 68(6):596-600.

7. Centurión OA, Isomoto S, Shimizu A, et al. The effects of aging on atrial endocardial electrograms in patients with paroxysmal atrial fibrillation. Clin Cardiol. 2003;26(9):435-438.

8. Centurión OA, Fukatani M, Konoe A, et al. Electrophysiological abnormalities of the atrial muscle in patients with sinus node dysfunction without tachyarrhythmias. Int J Cardiol. 1992;37(1):41-50.

9. Centurión OA, Shimizu A, Isomoto S, et al. Influence of advancing age on fractionated right atrial endocardial electrograms. Am J Cardiol. 2005;96(2):239-242.

10. Centurión OA, Shimizu A, Isomoto $\mathrm{S}$, et al. Repetitive atrial firing and fragmented atrial activity elicited by extrastimuli in the sick sinus syndrome with and without abnormal atrial electro grams. $\mathrm{Am} \mathrm{J} \mathrm{Med}$ Sciences. 1994;307(4):247-254.

11. Centurión OA, Isomoto S, Shimizu A, et al. Supernormal atrial conduction and its relation to atrial vulnerability and atrial fibrillation in patients with sick sinus syndrome and paroxysmal atrial fibrillation. $\mathrm{Am}$ Heart J. 1994;128:88-95.

12. Centurión OA, Isomoto S, Fukatani M, et al. Relationship between atrial conduction defects and fractionated atrial endocardial electrograms in patients with sick sinus syndrome. Pacing Clin Electrophysiol. 1993;16(10):2022-2033.

13. Centurión OA. Clinical implications of the $\mathrm{P}$ wave duration and dispersion: Relationship between atrial conduction defects and abnormally prolonged atrial endocardial electrograms. Int $J$ Cardiol. 2009;134(1):6-8.

14. Centurión OA, Shimizu A, Isomoto S, et al. Mechanisms for the genesis of paroxysmal atrial fibrillation in the Wolff-Parkinson-White syndrome: Intrinsic atrial muscle vulnerability vs. electrophysiological properties of the accessory pathway. Europace. 2008;10(3):294-302.

15. Shimizu A, Centurión OA. Electrophysiological properties of the human atrium in atrial fibrillation. Cardiovasc Res. 2002;54(2):302-314.

16. Hashiba K, Centurión OA, Shimizu A. Electrophysiological characteristics of human atrial muscle in paroxysmal atrial fibrillation. Am Heart J. 1996;131(4):778-789.

17. Engel TR, Luck JC, Leddy CL, et al. Diagnostic implications of atrial vulnerability. Pacing and Cardiac Electrophysiology PACE. 1979;2:208-213.

18. Engel TR, Gonzalez AD. Effects of digitalis on atrial vulnerability. Am J Cardiol. 1978;42(4):570-576.

19. Watson RM, Josephson ME. Atrial flutter I. Electrophysiologic substrates and modes of initiation and termination. $\mathrm{Am} \mathrm{J}$ Cardiol.1980;45(4):732-741.

20. Wyndham CRC, Amat-y-Leon F, Wu D, et al. Effects of cycle length on atrial vulnerability. Circulation. 1977;55(2):260-267.

21. Ohe T, Shimomura K, Inagaki M. The effects of cycle length on the fragmented atrial activity zone in patients with sick sinus syndrome. $J$ Electrocardiol. 1987;20(5):364-368.

22. Wells JL, Karp RB, Kouchoukos NT, et al. Characterization of atrial fibrillation in man: studies following open heart surgery. Pacing Clin Electrophysiol. 1978;1(4):426-438. 
23. Ohe T, Matsuhisa M, Kamakura S, et al. Relation between the widening of the fragmented atrial activity zone and atrial fibrillation. Am J Cardiol . 1983;52(10):1219-1222.

24. Shimizu A, Fukatani M, Tanigawa M, et al. Intra atrial conduction delay and fragmented atrial activity in patients with paroxysmal atrial fibrillation. Jpn Circ J. 1989;53(9):1023-1030.

25. Hashiba K, Tanigawa M, Fukatani M, et al. Electrophysiologic properties of atrial muscle in paroxysmal atrial fibrillation. Am J Cardiol. 1989;64(20):20J-23J.

26. Cosio FG, Palacios J, Vidal JM, et al. Electrophysiologic studies in atrial fibrillation. Slow conduction of premature impulses: a possible manifestation of the background for reentry. Am J Cardiol. 1983;51(1):122-130.
27. Dreifus LS, Wellens HJ, Watanabe Y, et al. Sinus bradicardia and atrial fibrillation associated with the Wolff-Parkinson-White syndrome. Am J Cardiol. 1976;38(2):149-156.

28. Wyndham C, Amat-y-Leon F, Wu D, et al. Effect of cycle length on atrial vulnerability. Circulation. 1977;55(2):260.

29. Rinne C, Klein GJ, Sharma AD, et al. Relation between clinical presentation and induced arrhythmias in the Wolff-Parkinson-White syndrome. Am J Cardiol. 1987;60(7):576-579.

30. Sung RJ, Castellanos A, Mallon SM, et al. Mechanism of spontaneous alternation between reciprocating tachycardia and atrial flutterfibrillation in the Wolff-Parkinson-White syndrome. Circulation. 1977;56(3):409-416. 